\title{
Bicomponent $\mathrm{AgCl} / \mathrm{PVP}$ nanofibre fabricated by electrospinning with gel-sol method
}

\author{
JIE BAI ${ }^{a, b}$, YAOXIAN LI ${ }^{a}$, LEI SUN ${ }^{a}$, CHAOQUN ZHANG ${ }^{a}$ and QINGBIAO YANG ${ }^{a, *}$ \\ ${ }^{a}$ Department of Chemistry, Jilin University, Changchun 130021, PR China \\ ${ }^{\mathrm{b}}$ Chemical Engineering College, Inner Mongolia University of Technology, Hahhot 010051, PR China
}

MS received 20 June 2008

\begin{abstract}
A new series of poly(vinyl pyrrolidone) (PVP) and silver chloride nanoparticles (AgCl) composite fibres have been synthesized by electrospinning and gel-sol technology. We used sol-gel process to prepare AgCl nanoparticles in the PVP solution, and then the solutions were electrospun to obtain AgCl/PVP composite nanofibres. The final products were thoroughly characterized by X-ray powder diffraction (XRD), transmission electron microscopy (TEM), and field-emission scanning electron microscopy (FESEM), which showed the formation of AgCl nanoparticles/PVP composite nanofibres.
\end{abstract}

Keywords. Electrospinning; nanoparticles; nanofibres; silver chloride.

\section{Introduction}

Recently, extensive studies have been carried out on the preparation and characterization of one-dimensional (1D) nanostructural materials owing to their unique properties and intriguing applications in many areas (Dag et al 1995; Mehnert et al 1998; Shen et al 2000; Zarur and Ying 2000). Especially, combination of different components in the nanosize range can obtain new composite materials that may hold the advantageous properties of each component of composite nanomaterials (Strawhecker and Manias 2000; Wang et al 2000; Wilder et al 2003; Bachand et al 2004). Among these composite nanomaterials, many recent efforts have been focused on the integration of inorganic nanoparticles into the interior of polymer nanofibres, and synthesis of inorganic/organic composite nanofibres. These composites obtained would offer opportunities to explore their novel optical, thermal, catalytic, magnetic, and electronic properties ( $\mathrm{Li}$ and $\mathrm{Xia}$ 2004; Demir et al 2004).

Amongst the methods of composite nanofibres fabricated, electrospinning is a simple, versatile, and useful technique. The diameters of fibres prepared by this method can range from tens of nanometers to several micrometers. The morphology of the electrospun fibres depends on the solvent and the solution properties, as well as other processing variables. The electrospinning progress is that a polymer solution was placed into a capillary that has a millimeter diameter nozzle, and a strong electrostatic force was applied to the solutions by a high static voltage. Under applied electrical force, the polymer solution is ejected

\footnotetext{
*Author for correspondence (baijie $@$ email.jlu.edu.cn)
}

from the nozzle. After the solvents are evaporated during the course of jet spraying, the nanofibres are collected on a grounded collector. As a result, nanoscale thin fibres are obtained (Reneker and Chun 1996; Huang et al 2003). Using electrospinning, various polymers have been fabricated by single polymer nanofibres successfully (Matthews et al 2002; Yang et al 2004; Gupta et al 2005; Kalayci et al 2005). Recently, some inorganic compounds have been incorporated in polymer nanofibre matrix by this technique. For instance, Wang et al fabricated $\mathrm{PbS}$ nanoparticles in polymer fibre matrices (Lu et al 2005). Jin et al (2005) prepared poly(N-vinylpyrrolidone) nanofibres containing silver nanoparticles by using electrospinning. Kim et al (2005) fabricated one-dimensional arrays of $\mathrm{Au}$ nanoparticles within poly(ethyleneoxide) (PEO) nanofibres. Silver chloride $(\mathrm{AgCl})$ inorganic nanoparticles are of both fundamental and technical interest due to their characteristic properties. In this work, we reported a new method for producing $\mathrm{AgCl} / \mathrm{PVP}$ composite nanofibres through electrospinning and gel-sol technology.

\section{Experimental}

\subsection{Sample preparation}

The PVP solution containing $\mathrm{AgCl}$ nanoparticles was synthesized according to the gel-sol method. In the preparation, an appropriate amount of PVP was dissolved in ethanol/water $(8 / 2)$ at a concentration of $8 \mathrm{wt} \%$. After stirring, appropriate amounts of $\mathrm{AgNO}_{3}$ were dissolved into the same volume of PVP solution which we prepared at $0^{\circ} \mathrm{C}$. The solution was stirred for about $10 \mathrm{~h}$ and then the same molar hydrochloric acid as Ag ions was added to the solution with stirring. 

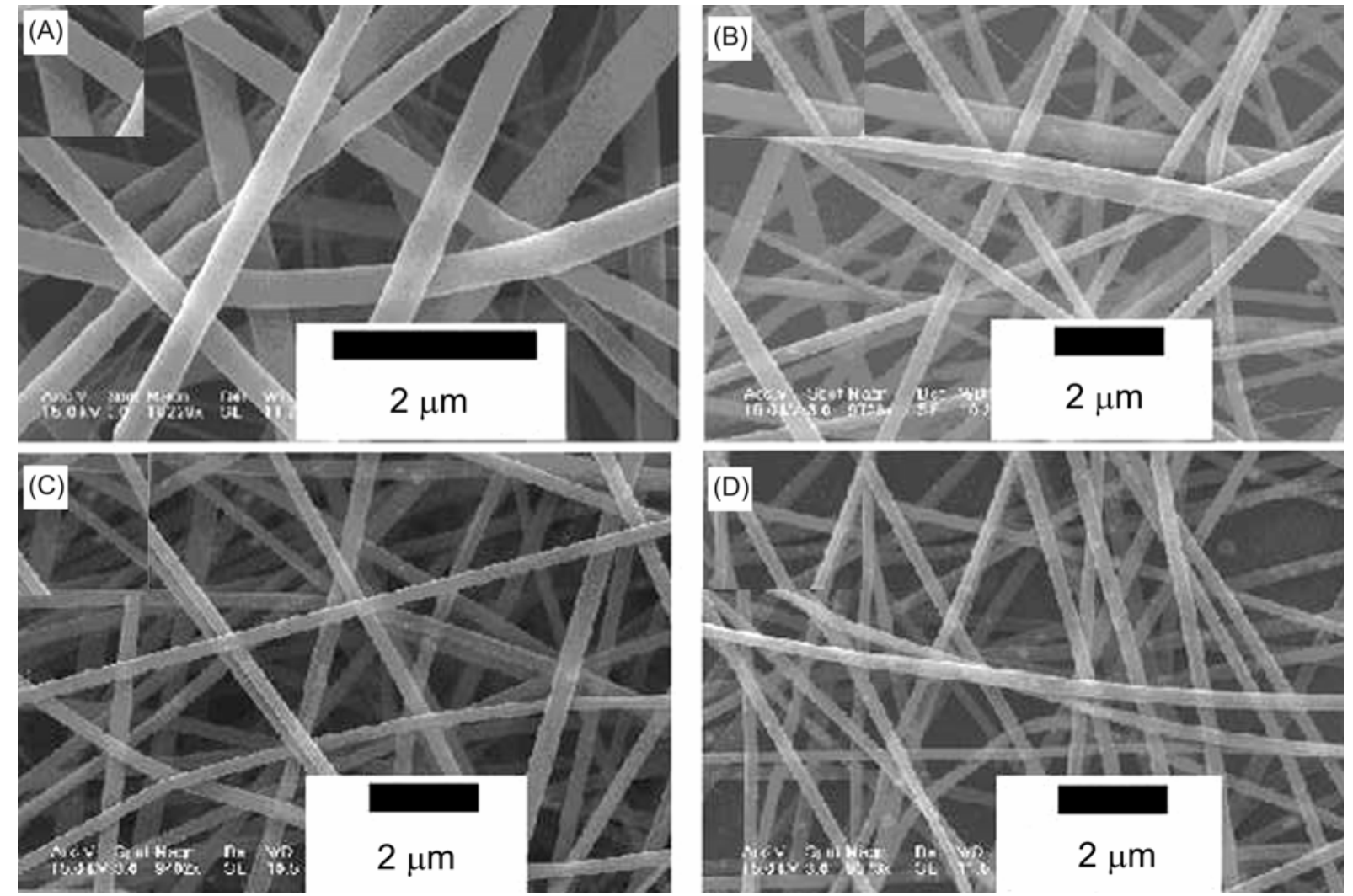

Figure 1. SEM images of pure PVP nanofibres and the PVP/AgCl composite fibres: (A) pure PVP, (B) the molar ratio of $\mathrm{AgCl}$ to $\mathrm{VP}$ is $1: 10,(\mathbf{C})$ the molar ratio of $\mathrm{AgCl}$ to $\mathrm{VP}$ is $1: 20$ and (D) the molar ratio of $\mathrm{AgCl}$ to $\mathrm{VP}$ is $1: 30$.

The schematic diagram of the electrospinning set up was shown in figure 1 . It consists of three major parts: a high-voltage power supply, a spinneret, and a collector plate (a grounded conductor). The above final solutions were electrospun to give composite fibres of $\mathrm{AgCl} / \mathrm{PVP}$. In the following text, the pure PVP fibres and $\mathrm{AgCl} / \mathrm{PVP}$ composite fibres electrospun from $8 \mathrm{wt} \%$ concentration of PVP ethanol solution are labelled as samples A, B, C and $\mathrm{D}$, respectively. The molar ratio of the $\mathrm{AgCl}$ to monomer of PVP in samples B, C, and D was calculated to be $1: 30,1: 20$, and $1: 10$, respectively. The voltage used for electrospinning was $15 \mathrm{kV}$, and the collection distance was $15 \mathrm{~cm}$. The temperature of electrospinning was controlled at $20^{\circ} \mathrm{C}$.

\subsection{Measurements}

Scanning electron microscopic (SEM) images were of the morphology of the electrospun fibres obtained by using a FEI XL30 ESEM. The morphologies of the AgCl/PVP fibres collected on carbon-coated copper grids were observed on a transmission electron microscopy (TEM, S-570, Hitachi). X-ray diffraction (XRD) pattern was obtained on a Rigaku Dmax (2000, CuK) X-ray diffractometer. The measurements of the X-ray photoelectron spectra (XPS) were performed by using a VG-Scientific ESCALAB 250 spectrometer with a monochromatic Al $\mathrm{K} \alpha \mathrm{X}$-ray source at $1486 \cdot 6 \mathrm{eV}$.

\section{Results and discussion}

Figure 1 shows the SEM images of electrospun pure PVP nanofibres and $\mathrm{AgCl} / \mathrm{PVP}$ composite nanofibres membranes were prepared. The electrospun nanofibres prepared using ethanol/water $(8 / 2 \mathrm{wt} / \mathrm{wt})$ as a solvent, and the concentration of PVP was $8 \mathrm{wt} . \%$ in the solution. The molar ratio of the $\mathrm{AgCl}$ to monomer of PVP in samples A, B, C, and D was $0,1: 30,1: 20$, and $1: 10$, respectively. The observed electrospun membranes consisted of fibres in the submicrometer range. Here, the average fibre diameter was found to decrease gradually with increasing concentration of $\mathrm{AgCl}$ nanoparticles. These results indicate that the fibre diameter of the electrospun PVP membranes are significantly affected by the $\mathrm{AgCl}$ nanoparticles content of the polymer solution used for electrospinning. The average diameter of the pure PVP nanofibres was about $256 \mathrm{~nm}$ (figure 1(A)). When the $\mathrm{AgCl}$ nanoparticles were introduced, the average diameter of nanofibres decreased. The average diameter of the $\mathrm{AgCl} / \mathrm{PVP}$ composite nanofibres was reduced to 345,320 and $290 \mathrm{~nm}$ (figures 1(B), (C) and (D)), respectively. 
The distribution of the $\mathrm{AgCl}$ nanoparticles can be validated directly by transmission electron microscopy (TEM). The TEM images of composite nanofibres are given in figure 2. The dark spots in the nanofibres are $\mathrm{AgCl}$ nanoparticles. When the mole ratio of $\mathrm{AgCl} / \mathrm{VP}$ was $1 / 30$ (figure 2(A)), the quantity of nanoparticles was sparse and the average diameter of $\mathrm{AgCl}$ particles was about $22 \cdot 2 \mathrm{~nm}$.

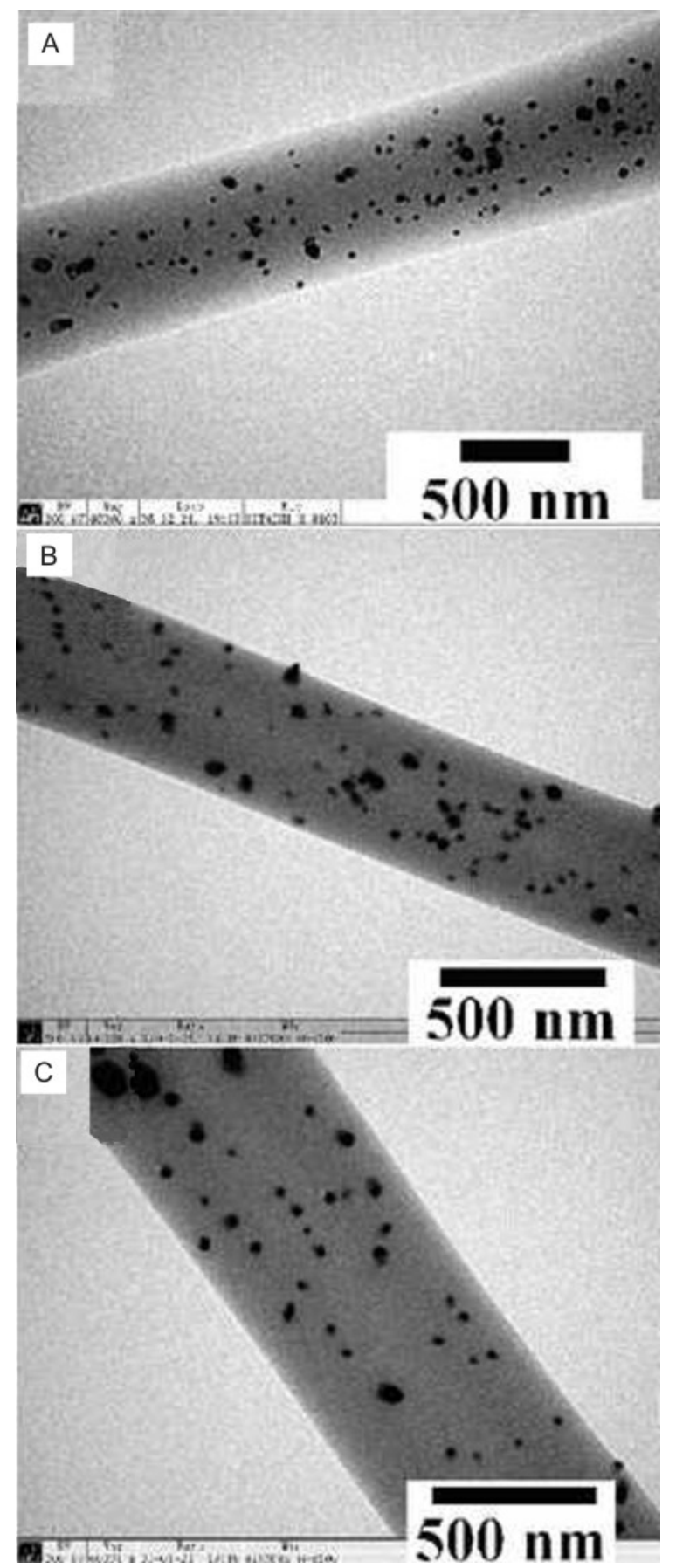

Figure 2. TEM images of the electrospun $\mathrm{PVP} / \mathrm{AgCl}$ composite fibres: A. the molar ratio of $\mathrm{AgCl}$ to $\mathrm{VP}$ is $1: 10$, B. the molar ratio of $\mathrm{AgCl}$ to $\mathrm{VP}$ is $1: 20$ and $\mathbf{C}$. the molar ratio of $\mathrm{AgCl}$ to $\mathrm{VP}$ is $1: 30$.
With the increase of molar ratio of $\mathrm{AgCl} / \mathrm{VP}$, the amount of prepared $\mathrm{AgCl}$ particles increased. And the average diameter of $\mathrm{AgCl}$ nanoparticles also was increased in size to $25 \mathrm{~nm}(\mathrm{AgCl} / \mathrm{PVP}(1 / 20))$ and $33.2 \mathrm{~nm}(\mathrm{AgCl} / \mathrm{PVP}$ $(1 / 10))$, respectively.

The XRD patterns of the nanofibres obtained from the experiments are given in figure 3 . An initial conclusion could be that the patterns in this figure are different. A strong peak appearing at $2 \theta$ value of about 20.55 in figure 3 (a) (pure PEO nanofibres) is assigned to crystalline PVP. The peak was significantly reduced in the product of the electrospinning of the PVP solution having $\mathrm{AgCl}$

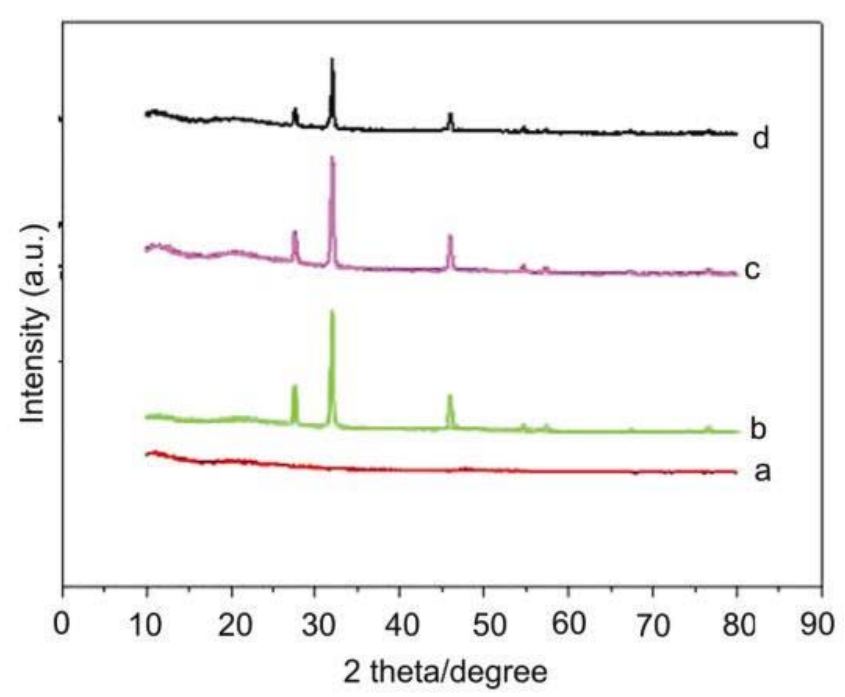

Figure 3. XRD patterns of pure PVP nanofibres and the $\mathrm{PVP} / \mathrm{AgCl}$ composite fibres: (a) pure $\mathrm{PVP}$, (b) the molar ratio of $\mathrm{AgCl}$ to $\mathrm{VP}$ is $1: 10$, (c) the molar ratio of $\mathrm{AgCl}$ to $\mathrm{VP}$ is $1: 20$ and (d) the molar ratio of $\mathrm{AgCl}$ to $\mathrm{VP}$ is $1: 30$

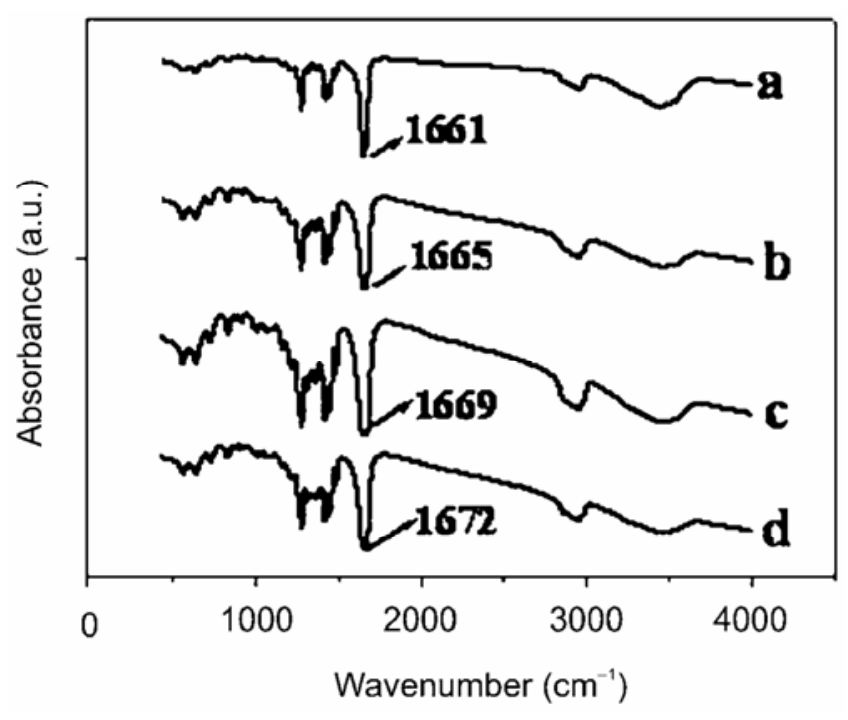

Figure 4. FTIR spectra of nanofibre film: pure PVP (a), the molar ratio of $\mathrm{AgCl}$ to $\mathrm{VP}$ is $1: 30$ (b), $1: 20$ (c) and $1: 10$ (d). 
nanoparticles, as shown in figure 3(b-d). The XRD pattern of the $\mathrm{AgCl} / \mathrm{PVP}$ composite nanofibres obtained also displays some peaks at $2 \theta$ values of $27.6^{\circ}, 32.05^{\circ}$, $46 \cdot 05^{\circ}, 54 \cdot 6^{\circ}, 57 \cdot 3^{\circ}, 67 \cdot 4^{\circ}, 74 \cdot 5^{\circ}$ and $76 \cdot 6^{\circ}$, which are related to cubic face-centred $\mathrm{AgCl}$ forms corresponding to scattering forms of (111), (200), (220), (311), (222), (400), (331) and (420), respectively.

Fourier transform infrared spectroscopy (FTIR) was a very useful technique to examine the structure and structure transformation of material. To prove that $\mathrm{AgCl}$ nanoparticles were modified by PVP in the fibres, we performed the measurements of FTIR. Figure 4 shows the FTIR spectra of the pure PVP nanofibre and those of $\mathrm{AgCl} /$ PVP composite nanofibres. Figure 4(a), due to the PVP, shows the peaks at about 2956,1661, 1466, $1285 \mathrm{~cm}^{-1}$ corresponding to the peak of $\mathrm{C}-\mathrm{H}, \mathrm{C}=\mathrm{O}, \mathrm{C}=\mathrm{C}$ and $\mathrm{C}-\mathrm{N}$, respectively. Figures 4(b), (c) and (d) show the FTIR spectrum of $\mathrm{AgCl} / \mathrm{PVP}(1 / 30), \mathrm{AgCl} / \mathrm{PVP}(1 / 20)$ and $\mathrm{AgCl} / \mathrm{PVP}(1 / 10)$ composite nanofibres, respectively. The strong absorption at $1661 \mathrm{~cm}^{-1}$ can be attributed to the carbonyl group stretching in the PVP. The curve (figure 4(a)) was compared with another cure and the results showed that the peak of $\mathrm{C}=\mathrm{O}$ changed in figure 4 , the peak of $\mathrm{C}=\mathrm{O}$ shifted to $1665 \mathrm{~cm}^{-1}$ (figure $4(\mathrm{~b})$ ), $1669 \mathrm{~cm}^{-1}$ (figure 4(c)) and $1671 \mathrm{~cm}^{-1}$ (figure 4(d)) in the FTIR of $\mathrm{AgCl} / \mathrm{PVP}$ composite nanofibres. This data results indicate that the existence of weak chemical bonding between the band of $\mathrm{C}=\mathrm{O}$ and $\mathrm{AgCl}$ nanoparticles.

\section{Conclusions}

In summary, this paper demonstrated a new synthetic route that we hybridize $\mathrm{AgCl}$ nanoparticles and poly(vinyl pyrrolidone) (PVP) on the basis of electrospun nanofibres. At first, $\mathrm{AgNO}_{3}$ are introduced into the solution of PVP. Then chloride ions react with silver ions to form $\mathrm{AgCl}$ nanoparticles by sol-gel technique. Lastly, using electrospinning method, PVP nanofibres containing $\mathrm{AgCl}$ nanoparticles are formed by electrospinning composite solution. FESEM images showed the morphology of composite nanofibres. TEM and XRD confirmed the presence of $\mathrm{AgCl}$ nanoparticles in the fibre. This simple approach is versatile and applicable to many other combinations of electrospun functional fibres and suitable inorganic nanoparticles.

\section{References}

Bachand G D, Rivera S B, Boal A K, Gaudioso J, Liu J and Bunker B C 2004 Nano Lett. 4817

Dag O, Kuperman A and Ozin G A 1995 Adv. Mater. 772

Demir M M et al 2004 Macromolecules 371787

Gupta P, Elkins C, Long T E and Wilkes G L 2005 Polymer 46 4799

Huang Z M, Zhang Y Z, Kotaki M and Ramakrishna S 2003 Compos. Sci. Technol. 632223

Jin W J, Lee H K, Jeong E H, Park W H and Youk J H 2005 Macro. Rapid Commun. 261903

Kalayci V E, Patra P K, Kim Y K, Ugbolue S C and Warner S B 2005 Polymer 467191

Kim G M, Wutzler A, Radusch H J, Michler G H, Simon P, Sperling R A and Parak W J 2005 Chem. Mater. 174949

Li D and Xia Y 2004 Adv. Mater. 161151

Lu X, Zhao Y and Wang C 2005 Adv. Mater. 172485

Matthews J A, Wnek G E, Simpson D G and Bowlin G L 2002 Biomacromolecules 3232

Mehnert C P, Weaver D W and Ying J Y 1998 J. Am. Chem. Soc. 12012289

Reneker D H and Chun I 1996 Nanotechnology 7216

Shen Y, Friend C S, Jiang Y, Jakubczyk D, Swiatkiewicz J and Prasad P N 2000 J. Phys. Chem. B104 7577

Strawhecker K E and Manias E 2000 Chem. Mater. 122943

Wang L, Rocci-Lane M, Brazis P, Kannewurf C R, Kim Y I, Lee W, Choy J H and Kanatzidis M G $2000 \mathrm{~J}$. Am. Chem. Soc. 1226629

Wilder E A, Braunfeld M B, Jinnai H, Hall C K, Agard D A and Spontak R J 2003 J. Phys. Chem. B107 11633

Yang Q B, Li Z Y, Hong Y L, Zhao Y Y, Qiu S L, Wang C and Wei Y 2004 J. Polym. Sci. Part B: Polym. Phys. 423721

Zarur A J and Ying J Y 2000 Nature 40365 